\title{
O LUGAR DO MARXISMO NA FORMAÇÃO DO EDUCADOR
}

\author{
THE PLACE OF MARXISM IN THE \\ FIELD OF TEACHER EDUCATION \\ LA PLACE DU MARXISME DANS \\ LE CHAMPS DE L'ÉDUCATION \\ EL LUGAR DEL MARXISMO EN \\ LA FORMACIÓN DEL EDUCADOR
}

\author{
Susana Vasconcelos Jiménez * \\ Laurinete Paiva Gonçalves ** \\ Luis Adriano Soares Barbosa ***
}

\section{RESUMO}

$O$ artigo toma por base uma pesquisa desenvolvida no campo da formação do educador, com vistas a aferir a presençalausência do marxismo no curso de pedagogia. Os dados foram coletados por meio do exame de programas disciplinares, questionários e entrevistas aplicadas a professores do curso de pedagogia da Universidade Estadual do Ceará. Os resultados apontam a formação do professor critico-reflexivo como o eixo dominante do curso, conforme o entendimento da maioria dos professores, enquanto a critica marxista comparece nesse contexto de forma rarefeita e, no mais das vezes, assaz problemática. Não obstante o processo desqualificatório que varreu o marxismo dos espaços acadêmicos, este parece fundamentar, numa perspectiva devidamente unitária e revolucionária, o desenvolvimento de duas disciplinas do curso tomado como objeto de estudo. $O$ artigo reafirma a relevância do marxismo $e$ defende um projeto de educação que aponte para a superação do capital.

Palavras-chave: Marxismo. Pedagogia. Formação do educador.

* Doutora em Educação pela United States International University (1982), com pós-doutorado em Educação, pela Unicamp (1993). Professora do Centro de Educação e Diretora do Instituto de Estudos e Pesquisas do Movimento Operário - IMO da Universidade Estadual do Ceará UECE (E-mail: susana_jimenez@uol.com.br).

** Pedagoga. Pesquisadora do Instituto de Estudos e Pesquisas do Movimento Operário - IMO da Universidade Estadual do Ceará - UECE (laurinetepedagoga@yahoo.com.br).

*** Pedagogo. Pesquisador do Instituto de Estudos e Pesquisas do Movimento Operário - IMO da Universidade Estadual do Ceará - UECE (lasba@zipmail.com.br). 


\section{INTRODUÇÃO}

O artigo apresenta uma síntese dos principais resultados de uma abrangente investigação desenvolvida em torno da docência no contexto das relaçôes entre trabalho e educação. Focalizando, de forma crítica, a atual política de formação do professor orientada pela supremacia dos interesses do mercado, tal pesquisa busca desvelar o sentido filosóficopolítico embutido na orientação rigorosamente não classista hoje hegemônica no campo da formação do educador. Desse modo, pretende contribuir para que a formação docente venha pautar-se por uma perspectiva teórica que permita o reconhecimento das profundas conexôes entre a prática educativa e a materialidade histórico-social. Ressalta, nesse sentido, a contrapelo das tendências dominantes, a perspectiva marxista de análise do complexo educacional, a partir da qual podemos postular que a formação docente se traduza na "preparação de seres humanos plenamente cultos, profundos conhecedores da história concreta dos homens" (SAVIANI, 2004, p. 22).

Duas ramificações da referida pesquisa estão na base do presente texto. A primeira buscou definir os eixos filosóficos e sociopolíticos que, de um modo geral, norteariam a formaçãa do educador, no espaço do curso de pedagogia, tomando como referência central a aproximação ou o distanciamento quanto a uma perspectiva educacional informada pela crítica marxista. A segunda tentou, por uma outra vertente, avaliar especificamente com que intensidade e em que perspectiva o referencial marxista penetraria o programa e o desenvolvimento das disciplinas oferecidas aos futuros pedagogos. Ambas as investigações elegeram como locus específico de análise o Curso de Pedagogia da Universidade Estadual do Ceará - UECE.

\section{DOS EIXOS NORTEADORES DO CURSO DE PEDAGOGIA}

O primeiro estudo assumiu como um dos seus objetivos fundamentais identificar as orientações teóricas que, na visão de seus professores, fundamentariam o curso de pedagogia. O questionário foi o instrumento utilizado e, por meio deste, dentre outros pontos, solicitava-se que cada sujeito (1) assinalasse, em uma listagem de 30 alternativas, aquelas que mais adequadamente expressariam os principais eixos norteadores do curso; e (2) declinasse espontaneamente o nome dos autores por ele privilegiados no desenvolvimento das disciplinas sob seu encargo. O questionário foi aplicado a uma amostra de 36\% (22 sujeitos), do total de 61 professores que, à época (2002), compunham o quadro docente responsável pelo desenvolvimento do curso em foco.

A maioria dos respondentes ( $57 \%$ do total) assinalou a formação do professor críticoreflexivo como o eixo norteador por excelência do Curso de Pedagogia.

Cabe destacar que, no rol de formulações relativas às possíveis linhas centrais do curso colocadas à disposição dos professores no referido questionário, constavam alternativas alusivas à inserção da educação na sociabilidade capitalista e a um possível papel mediador da educação na luta contra a reprodução do capital, a saber: análise das questôes sócio-educacionais na perspectiva do socialismo; a formação da consciência de classe; e a reflexão sobre o papel da educação na sociedade capitalista. Ao lado dessas, ainda, apresentavam-se 
opções vinculadas às formas históricas de organização dos trabalhadores e estudantes, respectivamente: a formação para a atuação junto ao movimento sindical; e o incentivo à participação no movimento estudantil. Desse conjunto de itens, aquele referente à reflexão sobre o papel da educação na sociedade capitalista fez jus a um índice significativo de menções, na verdade, ao terceiro maior índice, correspondente a 38\% do total de indicaçôes. No entanto, as demais alternativas do conjunto supracitado foram ignoradas pelos entrevistados, que não apontaram qualquer uma delas como eixo norteador do curso.

Esse resultado merece de nossa parte algumas apreciaçóes. Reconhecidamente, o apreço pela explicitação do papel social da educação tem sido historicamente cultivado pelos educadores, ainda que tal tenha se efetivado, prioritariamente, pelo viés funcionalista. A teorização acerca do papel ocupado pela educação na sociedade entendida como uma organização societária regida pelas determinaçôes capitalistas, por seu turno, ganhou significativo impulso no Brasil, na segunda metade do século passado, por meio das contribuições de alguns autores de vasta penetração no campo da educação. A dimensão histórico-social do fato educativo, tratada numa visão materialista dialética, constitui, por exemplo, uma das chancelas mais evidentes da produção de Dermeval Saviani.

Voltando aos dados obtidos na pesquisa, estes parecem indicar que, no contexto do curso, a reflexão sobre o lugar da educação na sociedade capitalista, se efetivamente elaborada, se desconectaria de uma disposição verdadeiramente anti-capitalista, não logrando, nesse sentido, desembocar no horizonte da ruptura com o capital, ou legitimar as estratégias de luta contra a presente ordem.

É justo reconhecer que a proposta voltada para a formação do professor crítico-reflexivo não assume, quanto à leitura efetuada sobre a sociedade ou o papel social da educação, qualquer pretensão de assentar seus preceitos sobre o arcabouço teórico-revolucionário do marxismo.

Em verdade, o desacordo com o ponto de vista marxista acerca da relação entre educação e prática social chega a ser mesmo explicitado em obras de referência quanto ao paradigma acima citado, a exemplo do livro Escola Reflexiva e Nova Racionalidade (2001), organizado por Isabel Alarcão, da Universidade de Aveiro (Portugal), um dos nomes internacionais de maior destaque dentre os que reafirmam a necessidade de adequar a educação às novas exigências postas pela sociedade global e tecnológica contemporânea, por meio de uma mudança paradigmática que conduza a escola na direção da formação reflexiva. ${ }^{1}$

$\mathrm{Na}$ referida obra, vale ainda destacar, Alarcão (2001, p. 22) defende enfaticamente o ideário cidadão, postulando que à escola reflexiva caberia não só preparar para o exercício da cidadania, mas, principalmente, praticar e viver a cidadania. Assim, ao mesmo tempo em que se define em favor de uma prática educativa reflexiva e emancipadora, o recorte teórico que contém tal paradigma elege a cidadania como o eixo por excelência da propositura pedagógica. Nesse sentido, a escola reflexiva desconsideraria, no sentido oposto àquele embutido numa abordagem marxista da educação, os limites que circunscrevem a cidadania ao horizonte da conquista de direitos políticos no escopo da ordem burguesa, tratando esta categoria como sinônimo de emancipação (ou liberdade). ${ }^{2}$

Caminhando adiante pelos resultados da pesquisa, devemos registrar que, com efeito, dentre os 46 autores declarados pelos professores entrevistados como aqueles que, com 
maior freqüência, visitariam as salas de aulas do curso de pedagogia, Paulo Freire desponta em primeiro lugar, obtendo um terço das indicações, 10 pontos percentuais acima de Dermeval Saviani e José Carlos Libâneo, que compartilharam o segundo lugar, cabendo a Selma Garrido Pimenta o terceiro, com 19\% das menções, sendo esta educadora, como bem sabemos, organicamente identificada com a proposta de formação do professor reflexivo.

À parte uma consideração mais rigorosa sobre os discutíveis fundamentos classistas da pedagogia de Freire, ou, no outro extremo, sobre as presumíveis aproximações operadas pelo autor da Pedagogia da Autonomia quanto ao chamado modelo das competências, o fato é que os dados obtidos na investigação aqui reportada indicam a ampla penetração do renomado educador brasileiro na experiência do curso.

Por outro lado, o empate entre Saviani e Libâneo num honroso segundo lugar não pode dispensar uma breve observação. Tendo o último, no passado, se encontrado na condição de aluno e orientando do primeiro, no presente, os dois encontram-se radicalmente apartados em suas posições teórico-práticas, uma vez que, ao contrário de Libâneo, Saviani permanece situado no campo do marxismo, donde deriva sua leitura do fenômeno educacional, como sua crítica acerca da política educacional vigente.

\section{A PRESENÇA/AUSÊNCIA DO MARXISMO NO CURRÍCULO DO CURSO DE PEDAGOGIA}

Com vistas a avaliar com que intensidade e em que perspectiva o referencial marxista penetra o processo formativo dos alunos do curso de pedagogia da UECE, iniciamos o segundo estudo, por examinar o programa de uma amostra de disciplinas ofertadas naquele curso, no ano de 2003.

A escolha das disciplinas recaiu sobre aquelas que compõem o núcleo curricular voltado para os fundamentos históricos, filosóficos e sociológicos da educação, acrescidas das disciplinas Introdução à Educação e Pesquisa Educacional, ao lado de uma amostra de disciplinas optativas, cujas denominações sugeririam que ali estivesse representada, em alguma medida, a contribuição do aporte marxista à problemática do trabalho e da educação dos trabalhadores.

Em suma, do total das 52 disciplinas que compóem o curso de pedagogia daquela instituição - 39 obrigatórias e 13 optativas - foram analisados os programas de uma amostra de 10 das obrigatórias e 2 das optativas. ${ }^{3}$

Após essa análise, foram realizadas entrevistas junto aos professores responsáveis pelas disciplinas, em cujos programas, foram reconhecidos, no todo ou em parte, elementos vinculados à contribuição de Marx e do marxismo. ${ }^{4}$ A entrevista partiu de uma questão básica que solicitava ao respondente esclarecer/confirmar se o referencial marxista embasaria o desenvolvimento de sua disciplina (ou se, ao contrário, o marxismo constaria do seu programa como um tópico ou uma unidade dentre as demais). A essa indagação básica, seguiam-se outras que, de um modo geral, (1) requeriam que o entrevistado justificasse a resposta concedida à questão de fundo; (2) esclarecesse pontos do programa de sua disciplina; e (3) se posicionasse quanto à relevância ou atualidade 
do marxismo, mormente do ponto de vista de suas contribuições para a ciência e a prática pedagógica.

Passemos, agora, ao registro dos programas das disciplinas selecionadas, acompanhado dos depoimentos prestados pelos professores entrevistados. Começamos por aquelas (no caso, duas) cujos professores expressaram-se sem reservas sobre o marxismo, admitindo, cada um a seu modo, fundamentar o desenvolvimento das disciplinas sob sua condução na leitura marxista da realidade social e da problemática educacional.

Marx encontra-se junto a Descartes, Rousseau, Adorno e Horkheimer dentre os autores a serem enfocados, conforme enuncia a ementa da primeira disciplina situada nessa categoria. "Tecer algumas reflexóes sobre educação e trabalho no pensamento de Marx, no sentido de demonstrar que a atividade do trabalho moderno converte-se na alienação, negação e desrealização do homem" constitui um dos objetivos específicos da disciplina (voltando-se os demais para as concepçōes fundamentais formuladas pelos outros pensadores citados na ementa). As unidades do programa, bem como as indicações bibliográficas, apresentam-se em consonância com os objetivos propostos. De Marx, constam, na bibliografia, os Manuscritos Econômicos e Filosóficos; de Marx e Engels, A Ideologia Alemã.

Esclareceu o professor, na entrevista, ter montado o programa da disciplina a partir do critério cronológico, fazendo, então, figurar Marx dentre os pensadores do Século XIX, destacando, contudo, a relevância e atualidade do autor para a reflexão do homem na sociedade capitalista. Destacou, ainda, que, ao tratar das demais correntes de pensamento constantes do programa da disciplina, examina seus respectivos pressupostos teóricos à luz do referencial marxista, argumentando demonstrar Marx embasamento teórico suficiente para a crítica de todos os grandes filósofos. Desse modo, define o marxismo como um desembocador, pois, considerando que vivemos na sociedade capitalista, alienante e desumanizadora, erigida sobre o princípio da propriedade privada, "todas as reflexōes levam necessariamente a Marx [...], a reflexão sobre qualquer teoria ou prática pedagógica desemboca no marxismo".

Em suma, o marxismo, além de constituir uma unidade do programa, apresenta conexôes com todos os outros estudos desenvolvidos, fundamentando toda a trajetória da reflexão construída na disciplina.

A segunda disciplina foi identificada, a partir de seu programa, como fundada, de maneira rigorosamente unitária, na perspectiva do marxismo, a saber, na ontologia marxiana e lukacsiana. ${ }^{5}$ Os termos de sua ementa anunciam os elementos essenciais do debate em torno da centralidade do trabalho na construção do gênero e da história humana; enfocando a relação trabalho e educação no contexto da crise estrutural do capital; a discussão em torno da mercantilização da educação brasileira sob a direção dos organismos de defesa dos interesses do capital internacional; a formação sindical e a educação do trabalhador, por fim, apontando para a concepção de escola unitária, de inspiração gramsciana. Em consonância com a ementa, os objetivos explicitam o propósito de explorar os conteúdos da disciplina com base na ontologia marxiana, começando pela reflexão sobre

[...] os elementos básicos à compreensão do trabalho como categoria no processo de produção e reprodução sociais; avaliando criticamente a tese da dissolução da centralidade do trabalho e 
da luta de classes no momento atual da sociedade capitalista; e concluindo pela apreciação do trabalho como princípio educativo, da educação unitária e politécnica no horizonte do socialismo.

A bibliografia lista duas obras de Marx (O Capital e os Manuscritos Econômico-filosóficos) e três de Marx e Engels (A Ideologia Alemã, O Manifesto Comunista e Escritos Inéditos sobre o Sindicalismo). Esses autores são acompanhados por Lukács (Ontologia do Ser Social); Mészáros (Marx: a Teoria da Alienação e Para além do Capital); além de autores nacionais cujas obras versam sobre questões da prática sócio-educacional, a partir da crítica marxista, mormente aquela de inspiração ontológica (Antunes, Chasin, Saviani, Coggiola, Lessa, Tonet e Duarte, dentre outros).

Confirmou o professor, através da entrevista, que, de fato, a fundamentação da referida disciplina está embasada nas discussões apresentadas por Marx e Lukács, lembrando ter sido Lukács um grande intérprete do marxismo no Século XX. Nas palavras do entrevistado:

Toda a disciplina tem como fundamentação a concepção de Marx sobre a história e sobre o ser social. Lukács, por sua vez, aparece ao lado de Marx, com suas importantes contribuições quanto ao entendimento do marxismo como uma ontologia do ser social, fundada na centralidade do trabalho como modelo originário da atividade genuinamente humana.

A partir da perspectiva ontológica, rebate a crítica repetida ad infinitum por seus opositores de que o marxismo teria desprezado o peso da individualidade e da subjetividade na construção da realidade social, reafirmando, além do mais, que "o marxismo continua atualíssimo, servindo-nos de guia para fazer o contraponto com o viés pósmoderno". Com base em Marx e Lukács, ainda, o professor alcança a realidade social contemporânea, para cuja apreensão vai também se apoiar em Mészáros, ex-discípulo de Lukács, para explicitar as características da crise estrutural de capital e suas implicações nos diferentes complexos sociais. A seu ver, ao instrumentalizar os alunos com base nas categorias construídas por Marx, a disciplina oferece a possibilidade do desvelamento da realidade, através de uma compreensão efetivamente crítica dos fenômenos sociais. Referindo-se às implicaçóes quanto à apropriação do marxismo em nossas vidas, explicitou:

Na medida em que eu me instrumentalizo teoricamente a partir do marxismo, a minha prática também tem que ser uma prática conseqüente com o projeto desempenhado por esse teórico da emancipação dos homens, da construção de um novo projeto de sociedade.

O professor confirmou, por fim, estudar com os alunos excertos das obras de Marx/Marx e Engels, citadas na bibliografia; textos de Lukács e Mészáros; além de buscar a contribuição daqueles pensadores brasileiros identificados com a perspectiva do marxismo, igualmente indicados na bibliografia.

Os três outros professores entrevistados, cada um à sua maneira, não obstante, segundo alegaram, realizem, em maior ou menor grau, estudos baseados em Marx e/ou no marxismo, em alguns casos, ainda, oferecendo subsídios sobre Marx e sua obra, negaram peremptoriamente fundamentar no referencial marxista o estudo dos conteúdos programáticos das disciplinas que ministram. 
No caso da primeira dessas disciplinas, o objetivo formulado exibe elementos de inspiração claramente marxista, uma vez que se define por: "proporcionar o exercício da reflexão sistemática e crítica, através do estudo de textos e temas, na tentativa de ler o real como totalidade concreta (grifo nosso)", enquanto seu programa assinala como parte do conteúdo programático, o estudo do materialismo histórico e dialético, dentre as principais escolas de pensamento. Estranhamente, porém, a bibliografia apresentada não faz menção a qualquer obra de Marx, ou de autores marxistas.

O conteúdo da entrevista concedida pelo professor da disciplina em foco foi, com efeito, informado por uma contradição de fundo em torno da afirmação/negação do marxismo.

Destarte, ainda que tenha definido o objetivo de sua disciplina em termos, sem dúvidas, afinados com a crítica marxista, negou que a disciplina estaria informada por esse referencial, asseverando ocupar o marxismo em seu programa um lugar equivalente àquele destinado às outras teorias. Paradoxalmente, contudo, ao tentar definir o que significaria tecer uma análise da realidade como totalidade concreta, aproximou-se mais uma vez de categorias atinentes ao campo do marxismo, declarando:

Ler o real como totalidade concreta significa desenvolver um senso crítico sobre a realidade, fazendo com que o indivíduo compreenda as questôes sociais, econômicas e políticas de sua época, posicionando-se como um sujeito consciente e crítico para que não seja tão facilmente manipulado pelas ideologias dominantes.

Além do mais, reconhece, segundo admitiu, ser o marxismo "capaz de fazer a crítica às demais correntes do pensamento, exibindo, ainda por cima, uma dimensão social, coletiva [...] clamando o homem para assumir seu papel de ser social e transformar sua realidade".

Ainda assim, por diversas vezes, ao longo da entrevista, declarou de forma enfática que o programa [da disciplina] não é embasado na doutrina (sic!) marxista.

A disciplina seguinte a ser aqui referida expõe em seu programa formulações que aludem diretamente às categorias da crítica marxista. $\mathrm{Na}$ ementa, por exemplo, assinala a inserção de classe e a práxis educativa, a educação e a transformação social. Como objetivos específicos, lista:

Identificar as características gerais da sociedade capitalista, sua composição, o papel do estado e seus aparelhos ideológicos, destacando a escola e o papel do educador; bem como, refletir sobre as implicaçōes políticas na educação através de um trecho de uma obra de Marx, observando sua crítica à sociedade capitalista e um ideal diferente de educação.

Em relação ao conteúdo programático, uma das cinco unidades volta-se para: $o$ pensamento econômico, político e sociológico: questōes introdutórias sobre a sociedade capitalista, o estado, a ideologia e a educação; Karl Marx, sua crítica à sociedade e um diferente ideal de educação. Um outro ponto que merece destaque no caso dessa disciplina é a indicação dos procedimentos metodológicos que prescrevem, por exemplo, para o desenvolvimento da unidade acima referida, o estudo de um texto sobre a sociedade capitalista, suas características, 
sua constituição, seus aparelhos, destacando a escola e o papel do educador; além de um seminário sobre a atualidade do Manifesto Comunista de Marx e Engels, procurando também realizar uma leitura pedagógica do mesmo. Ainda assim, a proposta da disciplina parece escapar do compromisso com as teses essenciais de Marx, quanto à revolução e ao socialismo, quando, por exemplo, elege o diálogo - não a revolução - como condiçãa de recuperação de nossa humanidade (Unidade I), esta, uma assertiva, a propósito, certamente ao gosto de Paulo Freire (autor, diga-se de passagem, mencionado com significativa apreciação em diferentes momentos da entrevista concedida pelo professor).

Vale observar que essa entrevista foi marcada, em larga medida, por um contundente desabafo em relação ao marxismo e aos marxistas, no qual o professor tendeu a generalizar os severos reducionismos efetivamente sofridos pelo pensamento de Marx, ao longo da história, advogando, nesse sentido, que "o marxismo, do jeito que está, está superado, caiu com o muro de Berlim”. Deplorou, também, o entrevistado, a forma autoritária, dogmática e unilateral como, no seu julgamento, o marxismo seria, por vezes, tratado na academia, onde, ainda mais, tal referencial seria desenvolvido através "da leitura de autores menores". Distinguindo-se, então, dos aludidos marxistas, o entrevistado declarou peremptória e repetidamente trabalhar Marx, porém, não trabalhar o marxismo. "Eu não trabalho o marxismo [...] eu trabalho Marx, um autor profundo, rico, criativo [...] que explicou a sociedade capitalista", prestando, inclusive, significativa contribuição ao campo educacional, pois: "cada obra de Marx ensina alguma coisa sobre educação". Explicitou, outrossim, ser Marx acatado em sua disciplina, "por respeito, porque ele é um clássico". Nessa condição, o velho gênio alemão faria parte do elenco de clássicos estudados em sua sala de aulas, ao lado, por exemplo, de Aristóteles, Platão e Paulo Freire. Em um outro momento da entrevista, contudo, deixando de lado suas reservas a respeito do marxismo e dos marxistas, o entrevistado apontou como um grande marxista Gyorgy Lukács, ressaltando no filósofo húngaro não propriamente o lugar por ele ocupado no escopo do marxismo, porém sua condição de pensador importante que incursionou com desenvoltura pelos campos da arte e da literatura: "Lukács era um autor muito rico, dominava literatura, dominava teatro, dominava a arte, tinha senso estético". Admitindo, ainda, a existência de "outros autores marxistas interessantes", presta tributo ao sociólogo paulista Ricardo Antunes. ${ }^{6}$

De todo modo, o entrevistado afirmou examinar com seus alunos textos de Marx, como O Manifesto Comunista, A Ideologia Alemã, Teses sobre Feuerbache, mesmo, O Capital, reafirmando, espontaneamente: "Não tenho medo de estudar o próprio Marx..."

A ementa da última disciplina desse conjunto anuncia, dentre outros pontos, o estudo das abordagens: positivismo, materialismo dialético e histórico. Em relação ao programa propriamente dito, uma das unidades indica a visão dos clássicos, destacando Marx e as classes sociais, ao lado de Weber e a ação social, e Durkheim e os fatos sociais; de outra unidade, consta $O$ materialismo dialético e histórico: sua contribuição. Não obstante o peso relativo do materialismo histórico no programa, incluindo a consideração sobre a complexa questão das classes sociais em Marx, a absoluta ausência de Marx (ou de qualquer autor marxista) nas referências bibliográficas é relativizada apenas quando é citado na bibliografia complementar posta ao final do programa o antológico Manifesto do Partido Comunista, escrito em co-autoria com Friedrich Engels.? 
Diferentemente do entrevistado anteriormente referido - o qual, como vimos, lançou uma crítica severa sobre os marxistas e o marxismo genericamente considerado, salvaguardando, porém, o reconhecimento do valor de Marx como um clássico dentre os grandes clássicos -, no caso do depoimento que será agora apresentado em suas linhas gerais, Marx foi, ele próprio, alvo da crítica, despontando como representante do mais autêntico determinismo economicista. Com efeito, indagado se o referencial marxista embasaria o desenvolvimento de sua disciplina, o entrevistado respondeu negativamente, relatando: "[...] eu faço uma síntese entre materialismo e idealismo, até por não aceitar completamente o determinismo econômico de Marx" (grifo nosso).

Surpreendentemente, contudo, tão dramático elemento identificado pelo professor no complexo teórico de Marx parece não impedi-lo de reconhecer uma dimensão de positividade no legado marxiano. Como, segundo supõe o entrevistado, "toda teoria tem algo de bom e algo de mal, [...] Marx pode dar respostas interessantes, como o positivismo pode dar respostas interessantes". Então, o determinismo economicista, aliado ao materialismo mecanicista, seria, por assim dizer, o ponto negativo do pensamento marxiano; enquanto, por exemplo, a capacidade de esclarecer "as relações causais que existem entre as coisas", permitindo que se compreenda que "o fenômeno não é simplesmente sua aparência [...]" se contaria entre os pontos positivos do legado marxiano. Como um clássico - dessa feita, ao lado de Weber e Durkheim -, Marx representaria, ainda, "não só a visão do clássico, mas a visão do clássico ligada às questôes físicas, às questôes emergentes das relaçôes sociais [...] numa condição, não somente de explicação da sociedade, como também, levando à concepção de práxis". É interessante observar que o entrevistado parece capaz de perceber, em um mesmo corpo teórico, o determinismo economicista ao lado daqueles elementos de explicitação do real para além de sua dimensão aparente, apontando, ainda, para a dinâmica e complexa noção de práxis! Ainda mais surpreendente é o fato de que, embora assuma o marxismo como uma filosofia da práxis, insiste num suposto caráter anti-humanista do marxismo, o que o leva a recomendar, no plano didático, "pegar uma parte materialista e uma parte idealista de uma forma sintetizada". No caso do tratamento específico do marxismo no contexto de sua disciplina, o entrevistado declara adotar como estratégia, "juntar um pouco de Karl Rogers ${ }^{8}$ com o Karl Marx, para tentar fazer essa dialética marxista um pouco mais humana" (grifo nosso).

Apresentaremos, por fim, as duas disciplinas cujo professor, à época da realização das entrevistas, já se encontrava ausente do quadro docente da UECE.

Uma das referidas disciplinas anuncia o estudo das teorias da educação com base em diferentes pensadores, quais sejam: Durkheim, Marx, Manheim, Baudelot, Establet e Snyders. O objetivo geral da disciplina revela a intenção de oferecer "uma fundamentação teórica de questôes básicas da educação num esforço de analisar a função da educação dentro da complexidade do mundo globalizado". Os objetivos específicos confirmam a preocupação com os chamados paradigmas sócio-educacionais emergentes, quando pretendem, por exemplo, "desenvolver a consciência ecológica de pertencer ao universo, assumindo uma atitude ética frente às questôes planetárias". Assim, enquanto a primeira unidade concentra-se nas concepçôes educacionais adotadas pelos pensadores evocados na ementa, anunciando, por exemplo, o sugestivo paralelo entre a sociedade quase-perfeita (Durkheim) e a sociedade mais-que-imperfeita (Marx), a segunda unidade 
intitula-se o paradigma educacional emergente. Nesse sentido, é interessante ressaltar que Marx e Engels compartilham o espaço das indicações bibliográficas com representantes da nova onda paradigmática (Leonardo Boff, Edgar Morin, Humberto Maturama), os quais, vale notar, conquanto se insurjam, em maior ou menor grau, contra as manifestaçōes mais agudas da tragédia contemporânea, apelando às idéias de paz, ética, consciência ou cidadania/cidadania planetária, expurgam da análise da realidade social as categorias propriamente classistas, abdicando do elemento central do legado marxiano: a superação do capital pela revolução socialista, como condição irrenunciável para a efetivação da sociedade e da humanidade emancipada.

A julgar pelo exame do programa, a segunda disciplina ministrada pelo mesmo professor parece pautar-se por igual perspectiva. Enquanto sua ementa e uma das unidades do programa sugerem uma aproximação dos estudos a serem realizados aos termos da crítica marxista, nomeadamente quando indicam a relação entre trabalho e educação, Boff, Morin e Maturama fazem-se mais uma vez presentes na bibliografia, lado a lado com Marx e Engels.

No caso das demais disciplinas da nossa amostra, duas não aludem a Marx ou às possíveis contribuiçôes do autor no campo educacional, emprestando, contudo, ênfase significativa ao método de Paulo Freire, representado pelas obras Pedagogia do Oprimido, Educação como Prática de Liberdade, e Educação e Mudança. Ou seja, o programa dessas disciplinas parece passar ao largo da questão controvertida, mas, certamente relevante para quem se dispõe a explorar o autor, relativa aos possíveis fundamentos marxistas de sua pedagogia libertadora. No caso da segunda disciplina, a bibliografia centra-se, fundamentalmente, em autores contemporâneos ou comentadores de Freire. Já no caso da terceira disciplina, não obstante seu objetivo geral sugerisse, em alguma medida, a consideração pela perspectiva histórico-materialista de compreensão do processo histórico e da educação, a presença de tal referencial não se confirma, quer no delineamento das unidades, quer nas indicações bibliográficas, este tópico, aliás, ausente do programa. As duas últimas disciplinas desse conjunto, até onde pudemos avaliar através da análise de seus programas, guardam distância de qualquer referência a Marx ou ao marxismo genericamente considerado.

Em suma, a pesquisa contabilizou que, do conjunto de doze 12 disciplinas que tiveram seus programas examinados, quatro (4) são marcadas pela ausência absoluta de qualquer menção direta ou indireta à crítica marxista; duas (2) disciplinas apresentam expressões ou formulações de objetivos ou ementas próximas a categorias do marxismo, sem que, em hipótese alguma, a presença de estudos marxistas se confirmasse na exposição dos conteúdos programáticos ou nas indicações bibliográficas. Em outras palavras, ementas ou objetivos parecem sugerir a escolha do referencial, mas tal escolha não transparece nos termos que explicitam as unidades de estudos propostas no programa. Sete (7) disciplinas, por sua vez, apresentam, efetivamente, tópicos, obras ou autores ligados ao legado de Marx. Dentre estas últimas, uma disciplina - optativa -, a julgar por seu programa, parece fundar-se integralmente na ontologia marxiana.

Dos cinco professores entrevistados, por sua vez, como vimos, dois, cada um a sua maneira, expressaram-se sem reservas sobre o marxismo, assumindo a importância de Marx tanto como um pensador que explicou com a devida profundidade e precisão os 
fundamentos e determinações da sociedade capitalista, como do ponto de vista da dimensão revolucionária do marxismo, a qual aponta para a práxis radicalmente superadora da ordem do capital.

Ambos os professores declararam trabalhar as disciplinas que ministram fundamentando-se no referencial marxista de leitura da realidade. Para tanto, conforme apontaram, exploram textos da autoria de Marx, ou de intérpretes marxistas, sobre pontos diversos da problemática do ser social, ou elaboram, à luz do marxismo, a crítica aos pressupostos teóricos assumidos pelos diferentes pensadores.

As demais entrevistas, somadas ao conteúdo programático proposto para a maioria das disciplinas apreciadas, deixam evidente, a nosso ver, o elevado teor de dificuldades em torno do tratamento conferido a Marx e ao marxismo pela maior parte dos professores que, pelo menos, se aventuram a abordá-lo em alguma medida, em suas salas de aulas.

Com efeito, podemos concluir que, no contexto analisado, o legado marxista é desfrutado, predominantemente, em fragmentos pouco conectados entre si, quando não se ajuntam estes com categorias atinentes a perspectivas contrapostas de análise do real. Em alguns casos, empregam-se terminologias ou formulações claramente afinadas com o campo marxista, porém as unidades do programa ou as indicações bibliográficas não se coadunam com tal orientação; em outros, o referencial marxista é levado a travar um diálogo esdrúxulo com os chamados paradigmas emergentes, desconsiderando o fato de que estes cumprem, precisamente, o papel de superar a suposta obsolescência do marxismo. Em outras instâncias, ainda, situam Marx e o marxismo em campos opostos, tomando o marxismo, impreterivelmente, como doutrina, como dogma, sendo, como tal, rejeitado. ${ }^{9} \mathrm{Ou}$, então, aprecia-se o Marx filósofo, clássico dentre os grandes clássicos, desconsiderando, contudo, sua condição de teórico da revolução proletária. Por fim, reparte-se Marx entre o bom - o que contribui para uma noção de práxis, o desenvolvimento de uma consciência crítica - e o mau - aquele do determinismo econômico, avesso ao humanismo, incapaz, em suma, de reconhecer o ser social para além da esfera do homo economicus.

É importante observar que, para muitos autores, a desqualificação generalizada do marxismo merece ser analisada em seus significados e implicaçôes mais profundas. Estes afrontam particularmente a associação indevidamente traçada entre o marxismo, o socialismo e a tragédia stalinista, condenando, ainda, com absoluta severidade, o divórcio comumente sagrado entre o Marx filósofo, analista da sociedade do capital, e o Marx pensador revolucionário comprometido com o comunismo.

Katz (1996, p. 22), por exemplo, reconhece que a atual reação [desqualificatória] "contra o marxismo é uma conseqüência direta do desmoronamento dos regimes burocráticos da Europa e Ásia”, porém, propugna que atribuir ao marxismo a responsabilidade pela opressão totalitária ali consumada "implica aceitar uma identidade usurpada pelo stalinismo e que causou as maiores confusóes e retrocessos ao materialismo dialético" (1996, p. 23).

Cerdeira (1999, p. 131), por sua vez, reconhece que:

[...] a última década esteve marcada por um dos maiores ataques ideológicos que o marxismo sofreu no século XX. Fruto de uma contra-ofensiva político-ideológica levada a cabo pelos 
ideólogos, partidos, líderes políticos e meios de comunicação do imperialismo, tal ofensiva se estendeu às universidades refletindo-se no avanço de ideologias reacionárias.

Vai mais adiante o autor, para ressaltar: "Anuncia-se a atualidade de Marx como analista do capitalismo, mas condena-se o defensor da revolução socialista, do internacionalismo, da organização da classe em partido e do potencial revolucionário da classe operária". Assim, arremata: "Ao separar o Marx analista do Marx revolucionário procura-se esterilizar o próprio marxismo".

Sobre esse último aspecto, chama a atenção, a força da argumentação construída por nosso saudoso Florestan Fernandes, o qual, como se pode bem lembrar, tocou com sua lucidez muitas questôes cruciais relativas à formação do educador. Ora, para o sociólogo educador (1995, p. 33),

Marx não figura apenas como um clássico, entre os fundadores das ciências sociais e do comunismo. É um cientista social e um pensador comunista [...] as conclusões a que chegou fazem parte dos quadros da reflexão científica e da atividade política revolucionária que se reconstituem a cada instante $[\ldots]$

Concluindo o autor à página 39 da mesma obra: “Um verdadeiro 'diálogo com Marx' teria de surgir nessa confluência da investigação científica com o desenvolvimento histórico e os fins essenciais do socialismo".

\section{NOTA CONCLUSIVA}

Como seria de se esperar perante as condições de alienação alojadas na presente materialidade, os resultados da pesquisa denunciam o distanciamento fincado pela maioria das disciplinas ofertadas no curso de pedagogia, quanto à abordagem marxista do fenômeno educacional, mais ainda quando se toma em consideração a perspectiva do socialismo como eixo norteador da formação docente. Não podemos inferir do fato que referido distanciamento traduza, necessariamente, a vigência, no contexto do curso, de uma postura de aceitação irrestrita do status quo, muito menos uma despreocupação leviana a respeito da problemática da formação docente. Um dado, porém, parece irrefutável: salvo honrosas exceções, o curso não estaria casando uma mais ou menos acentuada orientação crítica em torno do papel da escola na sociedade capitalista à necessidade de superação do sistema que, em última análise, produz a escola que temos. Muito ao contrário, a julgar pelos resultados majoritários da pesquisa, a resposta à questão Qual a escola que queremos?, volta e meia proclamada nas salas de aula, deverá caber, integralmente, na sociedade que temos...

A despeito das questôes apontadas acima, os resultados dessa investigação não podem desapreciar o comparecimento, ainda que marcadamente irregular e problemático, do marxismo e, mais ainda, da chamada ontologia marxiana, no espaço de formação pedagógica considerado na pesquisa. Num cenário de negação cerrada do marxismo, em nome do recrudescimento idealista embutido na infinitude de visóes que se derramam 
constantemente sobre a (pós)moderna academia, não se poderá, a bem do rigor, menosprezar a prática rigorosamente anti-capitalista de professores, que, mesmo em absoluta minoria, fundam no marxismo o desenvolvimento dos conteúdos disciplinares sob sua competência. Não se deverá desconsiderar, outrossim, a importância de que, em uma sala de aulas do mesmo curso, seja reafirmada a atualidade do Manifesto Comunista; que se avalie, com o apoio de autores marxistas contemporâneos como Mészáros, os desafios postos pelo capitalismo contemporâneo; ou se decifrem os pressupostos da escola unitária de Gramsci.

Encerrando nossas considerações, devemos declarar que o entendimento do marxismo como uma perspectiva unitária de análise da realidade, sobre o que vimos insistindo, ao longo do presente texto, não pretende autorizar a adoção de uma postura dogmática, negando a importância de que a formação do educador contemple o estudo de outras escolas de pensamento. Ao contrário, faz-se necessário defender uma formação abrangente e rigorosa, fundada no estudo das idéias formuladas pela miríade de teóricos clássicos e contemporâneos que escreveram/vêm escrevendo a história do pensamento, bem como seus rebatimentos com relação à compreensão e ao tratamento do fenômeno educacional. Por outro lado, não podemos perder de vista a relevância do conhecimento radicalmente crítico, que apanha o movimento das idéias para além de seus contornos epistemológicos, na tentativa de alcançar suas determinações no plano essencialmente ontológico.

\section{Notas}

1. É oportuno conferir, nesse sentido, o estudo assinado por Iria Brzezinski, na obra citada.

2. Adverte Tonet, nesse sentido, que "Reconhecer as limitaçôes intrínsecas da cidadania não significa, de modo nenhum, menosprezar a importância que ela teve e tem no processo de autoconstrução do ser social. Significa apenas reconhecer que ela integra necessariamente - ainda que de modo contraditório e tensionado - a sociabilidade regida pelo capital". A respeito de uma discussão ampla e rigorosa acerca da problemática da cidadania, é importante consultar o autor, sobretudo, em sua obra Educação, cidadania e emancipação (2005).

3. Foram omitidos os títulos das disciplinas, bem como os nomes dos professores entrevistados, uma vez que a pesquisa volta-se para uma compreensão do grau de penetração do marxismo no contexto da formação pedagógica de um modo geral, dispensando a identificação quanto ao tratamento aferido à questão por qual(is) professor(es), em qual(is) disciplina(s) ministrada(s).

4. À época da aplicação do instrumento, o professor que ministrara duas das referidas disciplinas ausentara-se da instituição, em razão de aposentadoria, não tendo sido, então, possível entrevistá-lo.

5. Para Nicholas Tertulian (1996), um dos grandes estudiosos de Lukács, aquele filósofo húngaro realiza, através de sua obra de maturidade, representada pela Estética e, posteriormente, pela "Ontologia do Ser Social, a mais ambiciosa e a mais importante reconstrução filosófica do pensamento de Marx", superando duas severas distorçōes imputadas historicamente à herança marxiana: "(1) o determinismo economicista que anula a eficácia dos demais complexos da vida social e (2) a interpretação teleológica - dogmática - que considera toda ação histórica um passo no caminho da realização de um fim imanente ou transcendente".

6. Ricardo Antunes, da Universidade Estadual de Campinas - Unicamp, é um dos mais importantes estudiosos das questóes do trabalho no capitalismo contemporâneo, encaradas à luz da ontologia marxiano-lukacsiana. 
7. Weber e Durkheim são igualmente citados apenas na bibliografia complementar, enquanto na bibliografia básica constam, fundamentalmente, manuais didáticos relativos ao campo de estudo em foco.

8. Karl Rogers, psicólogo e educador norte-americano, crítico ferrenho do behaviorismo educacional representado por Skinner dentre outros, defendeu um ideário educacional fundado na defesa da liberdade de aprender, da aprendizagem significativa e do ensino não diretivo.

9. Lembra Tonet (1997, p. 229), oportunamente, que "a acusação de dogmatismo, [...] é desprovida de qualquer fundamento, quando ela se refere às figuras mais expressivas da tradição marxista”.

\section{Referências *}

ALARCÃO, Isabel (Org.). Escola reflexiva e nova racionalidade. Porto Alegre: Artmed, 2001. ARCÁRY, Valério. As esquinas perigosas da história. São Paulo: Xamã, 2004.

BATALHA, Cláudio. A difusão do marxismo e os socialistas brasileiros na virada do Século XIX. In: MORAES, João Quartim de. História do marxismo no Brasil. Campinas: Edunicamp, 1995. p. 11-44. BRZEZINSKI, Iria. Fundamentos sociológicos, funções sociais e políticas da escola reflexiva e emancipadora. In: ALARCÃO, Isabel (Org.). Escola reflexiva e nova racionalidade. Porto Alegre: Artmed, 2001. p. 65-82.

CERDEIRA, Bernardo. O grande desafio. Marxismo, partido e revolução. Crítica Marxista, n. 8. São Paulo: Xamã, 1999. p. 128-135.

COGGIOLA, Osvaldo. Marxismo e classes sociais na atualidade. In: KATZ, Cláudio; BRAGA, Ruy; COGGIOLA, Osvaldo. Novas tecnologias: crítica da atual reestruturação produtiva. São Paulo: Xamã, 1995. p. 137-146.

FERNANDES, Florestan. Em busca do socialismo. São Paulo: Xamã, 1995.

KATZ, Cláudio. Pós-Marxismo: uma crítica. In: COGGIOLA, Osvaldo (Org.). Marxismo hoje. São Paulo: Xamã, 1996. p. 21-82.

MÉSZÁROS, István. Beyond capital. London: Merlin Press, 1998.

. A crise estrutural do capital. Revista Outubro, n. 4, p. 7-16, 2000.

SAVIANI, Dermeval. O trabalho como princípio educativo frente às novas tecnologias. In: FERRETTI, Celso João et al. (Orgs.). Novas tecnologias, trabalho e educação: um debate multidisciplinar. Petrópolis: Vozes, 1994. p. 147-164.

. Perspectiva marxiana do problema subjetividade-intersubjetividade. In: DUARTE, Newton (Org.). Crítica ao fetichismo da individualidade. São Paulo: Autores Associados, 2004. p. 21-45. TERTULIAN, Nicholas. Uma apresentação à ontologia do ser social. Crítica Marxista, São Paulo: Brasiliense v. 1, n. 3. p. 54-69, 1996.

TONET, Ivo. Educação, cidadania e emancipação humana. Ijuí: Edunijuí, 2005. . Socialismo e Democracia. Práxis, Belo Horizonte: Projeto Joaquim de Oliveira, n. 8, p. 29-46, 1997.

* As fontes apresentadas dizem respeito somente àquelas citadas pelos autores do texto, excluindo as obras referidas pelos professores entrevistados no processo de investigação. 


\section{The place of Marxism in the field of teacher education}

\section{Abstract}

The article is based upon an investigation in the field of teacher education, which intended to verify the presencelabsence of Marxism within the context of the Pedagogy Course. Data was gathered through the analysis of curricular programs; questionnaires and interviews applied to instructors at Ceará State University (Brazil). The results indicate the critical-reflexive teacher as the Course's central point of reference for the majority of the subjects reached by the research. Meanwhile, the presence of Marxist critique within that context was found to be scarce and, all in all, rather problematic. On the other hand, despite the unqualifying process that swept it away from the academic world, Marxism, taken from a unitary and revolutionary standpoint, appears to support the development of two of the Course's programs. The article reaffirms the relevance of Marxism and defends an educational project which points beyond a capitalistic perspective.

Keywords: Marxism. Pedagogy. Teacher education.

\section{La place du marxisme dans le champs de l'éducation Résumé}

Ce texte est basé sur une recherche en matière de formation de maîtres qui avait pour but de vérifier la présencelabsence du marxisme dans le contexte du curriculum du cours de Pédagogie. Les données ont été recueillies au travers de l'analyse des programmes curriculaires, questionnaires et entrevues avec les professeurs à l'Universidade Estadual do Ceará (Brésil). Les résultats indiquent que le maître critique et réflexif constitue le point central de référence pour la majorité des sujets atteints par la recherche. Entre temps, la présence de la critique marxiste dans le contexte s'est révélée rare et, en plus, plutôt problématique. D'autre part, en dépit de processus de déqualification qui l'a balayé loin du monde académique, le marxisme, pris d'un point de vue unitaire et révolutionnaire, apparaît comme support à deux plans de cours. L'article reconfirme la pertinence du marxisme et défend un projet d'éducation qui pointe vers une perspective au-delà du capital.

Mots clefs: Marxisme. Pédagogie. Formation de maîtres.

\section{El lugar del marxismo en la formación del educador}

Resumen

El artículo se basa en una pesquisa desarrollada en el campo de la formación del educador, visando a verificar la presencial ausencia del Marxismo en la carrera de pedagogía. Los datos fueron colectados a través del examen de planes de asignaturas, cuestionarios y entrevistas aplicadas a profesores de la carrera de pedagogía de la Universidade Estadual do Ceará. Los resultados apuntan la formación del profesor crítico-reflexivo como el eje dominante de la carrera, según el entendimiento de la mayoría de los profesores, mientras la critica marxista surge en ese contexto de forma rarefecta y, no más de las veces, asaz problemática. No obstante el proceso descalificatório que barrió el marxismo de los espacios académicos, este parece fundamentar, en una perspectiva unitaria y revolucionaria, el desarrollo de dos asignaturas de la carrera aqui investigada. El articulo reafirma la relevancia del marxismo y defiende un proyecto de educación que apunte para la superación del capital.

Palabras-clave: Marxismo. Pedagogía. Formación del educador.

Recebido: 26.09 .2006

Aceito: 24.01 .2007 
